\title{
Crenças de professores e futuros professores portugueses sobre a reprovação no $2^{\circ}$ ano de escolaridade
}

\author{
Natalie Nóbrega Santos' (D) \\ Vera Cristina Monteiro' (D)
}

\section{RESUMO}

Este estudo procurou investigar as crenças de professores e futuros professores estudantes de cursos de formação de professores - do $1^{\circ}$ ciclo do ensino básico em Portugal relacionadas à reprovação no $2^{\circ}$ ano de escolaridade. Participaram 137 professores em serviço e 99 estudantes em formação (idades entre 19 e 65 anos, 96,2\% do sexo feminino), que responderam a um questionário sobre os efeitos acadêmicos gerais e socioafetivos da reprovação, bem como os efeitos da reprovação precoce. Os resultados mostraram uma grande variabilidade nas crenças, com os professores em exercício apresentando crenças mais positivas que os estudantes. Existe também uma associação entre as crenças dos professores e as suas práticas. As crenças parecem ter um impacto na prática docente, conseguindo sobrepor-se às políticas educacionais e às recomendações científicas.

PALAVRAS-CHAVE

reprovação escolar; professores de educação básica; crenças; práticas educativas.

'Instituto Universitário (ISPA), Centro de Investigação em Educação (CIE-ISPA), Lisboa, Portugal. 


\title{
IN-SERVICE AND PRE-SERVICE PORTUGUESE TEACHERS BELIEFS ABOUT FAILURE IN THE $2^{\text {ND }}$ GRADE
}

\begin{abstract}
This study sought to investigate the beliefs of teachers and students of teacher training courses for the first cycle of basic education in Portugal about grade retention in the second grade. 137 in-service teachers and 99 undergraduate students (aged between 19 and 65 years, 96.2\% female) participated in the survey and answered a questionnaire about the general and socio-affective academic effects of grade retention and the effect of early grade retention. The results showed great variability in teachers' beliefs, with in-service teachers presenting more positive beliefs than those of students. There was also an association between teachers'beliefs and their practices. Beliefs seem to have an impact on teaching practices, managing to override educational policies and scientific recommendations.
\end{abstract}

KEYWORDS

grade retention; basic education teachers; beliefs; educational practices.

\section{CREENCIAS DE MAESTROS Y FUTUROS \\ MAESTROS PORTUGUESES SOBRE EL FRACASO ESCOLAR EN EL $2^{\circ}$ GRADO}

\section{RESUMEN}

Este estudio investigó las creencias de maestros y futuros maestros estudiantes de cursos de formación de profesores - del primer ciclo de educación básica en Portugal ante el fracaso escolar en el $2^{\circ}$ año de escolaridad. En el estudio participaron 137 profesores en servicio y 99 estudiantes de pregrado (de 19 a 65 años, 96,2\% mujeres) que respondieron un cuestionario sobre los efectos académicos generales y socioafectivos del fracaso escolar, así como los efectos del fracaso en los primeros años de escolaridad. Los resultados mostraron una gran variabilidad en las creencias, presentando los profesores en funciones concreencias más positivas que los estudiantes. También existe una asociación entre las creencias de los profesores y sus prácticas. Las creencias parecen incidir en la práctica docente, logrando anular los efectos de las políticas educativas y las recomendaciones científicas.

PALABRAS CLAVE

fracaso escolar; profesores de educación básica; creencias; prácticas educativas. 


\section{INTRODUÇÃO}

A reprovação escolar é uma prática utilizada com alunos que apresentam dificuldades acadêmicas. Nessa situação, o aluno permanece no mesmo ano curricular por um ano letivo adicional (Nunes, Reis e Seabra,2018). O objetivo é oferecer uma oportunidade ao aluno de melhorar a sua aprendizagem; no entanto, a reprovação é considerada controversa, visto que resultados de estudos internacionais indicam que essa prática não ajuda a melhorar, em longo prazo, o desempenho acadêmico ou socioafetivo dos alunos (Crahay, 2007; Goos et al., 2013a), apesar de haver melhorias ocasionais a curto prazo (Allen et al., 2009; Nunes, Reis e Seabra, 2018). Em harmonia com esses resultados, a legislação portuguesa assinala que a reprovação deverá ocorrer apenas em casos excepcionais (Portugal, 2016, 2018).

Apesar dessas indicações, a prática da reprovação não é excepcional em Portugal, mas um procedimento relativamente comum na maioria dos anos escolares (OECD, 2016; DGEEC, 2019), em particular no $2^{\circ}$ ano, no qual os índices de reprovação variam entre 4,8 e 10,8\%, dependendo da região (DGEEC, 2019).

Alguns estudos sugerem que as elevadas taxas de reprovação observadas em Portugal estão relacionadas a uma forte crença da sociedade nos benefícios de repetir o ano escolar, especialmente nos primeiros anos de escolaridade (EURYDICE, 2011; Goos et al., 2013b; CNE, 2015; Rodrigues et al., 2017; Santana, 2019). As crenças são um conjunto de representações conceituais que armazenam o conhecimento geral de objetos, pessoas e eventos, assim como as suas características e as suas relações (Hermans, Van Braak e Van Keer, 2008); são julgamentos individuais acerca da autenticidade ou falsidade de uma proposição (Pajares, 1992), estando caracterizadas por um considerável grau de convicção. As crenças têm sido identificadas como precursoras do comportamento e são consideradas um indicador importante das decisões individuais tomadas pelos professores (Borko, Roberts e Shavelson, 2008; Buehl e Beck, 2015).

Uma vez que as crenças podem ser decisivas na tomada de decisão (Borko, Roberts e Shavelson, 2008; Buehl e Beck, 2015), torna-se relevante conhecer as crenças dos professores sobre a reprovação para compreender por que, em Portugal, se persiste na utilização dessa prática, especialmente no $2^{\circ}$ ano do ensino básico. Consequentemente, este estudo teve como objetivo geral caracterizar e compreender as crenças em relação à reprovação no $2^{\circ}$ ano de escolaridade dos professores em serviço e dos futuros professores (estudantes de ensino superior inscritos nos cursos de formação de professores) do $1^{\circ}$ ciclo de ensino básico português.

\section{CRENÇAS SOBRE A REPROVAÇÃO}

Os estudos sobre as crenças relacionadas à reprovação têm identificado que uma grande parte dos professores, particularmente aqueles que lecionam os primeiros anos de escolaridade, acredita que a reprovação traz vários benefícios aos alunos em termos de aprendizagem e desenvolvimento de competências, apresentando crenças positivas sobre sua eficácia (Tomchin e Impara, 1992; Bonvin, 2003; Witmer, Hoffman e Nottis, 2004; Range et al., 2012; Crahay, Marbaise e Issaieva, 2013; Ribeiro et al.,2018). Essas investigações indicam que os professores consideram que a repro- 
vação é necessária para o futuro sucesso escolar dos alunos, que é mais indicada nos primeiros anos de escolaridade (pois terá um menor impacto negativo na autoestima e no autoconceito das crianças), e que é especialmente aconselhada quando o aluno é considerado imaturo. Em Portugal, o CNE (2015) aponta a existência de uma ideia recorrente, em termos sociais, de que a reprovação é um procedimento natural, promotor de aprendizagem. Da mesma forma, estudos de Rodrigues et al. (2017) e Santana (2019) observaram que a maioria dos professores considera que a reprovação tem mais vantagens do que desvantagens. Mesmo reconhecendo os riscos da desmotivação e do abandono escolar, os professores consideram que a reprovação é útil para a aquisição e consolidação das aprendizagens e para a recuperação das dificuldades, em particular para aquelas que revelam imaturidade. Consequentemente, a maioria dos professores que participaram no estudo considera que a reprovação deve acontecer desde o $1^{\circ}$ ano de escolaridade, pois veem a prática como uma oportunidade e não como um problema (Rodrigues et al., 2017).

Diversas pesquisas também têm estudado as crenças dos futuros professores, isto é, estudantes do ensino superior em cursos de formação de professores. Boraita (2015), em uma amostra de estudantes suíços, constatou que estes têm uma opinião desfavorável em relação à reprovação. Não acreditam que a reprovação possa ter uma função de regulação cognitiva verdadeiramente eficaz, e são ainda da opinião de que a reprovação traz consigo consequências socioafetivas negativas, nomeadamente ao nível do autoconceito e autoestima do aluno. $\mathrm{O}$ estudo desenvolvido por Boraita e Marcoux (2016) colocou em evidência que essas crenças estão relacionadas à cultura escolar de cada país. Com amostras de futuros professores suíços, belgas e franceses, os autores constataram que os estudantes belgas têm crenças mais favoráveis à prática da reprovação do que os estudantes franceses e suíços, sugerindo ainda que essa diferença estaria relacionada a uma maior importância dada às notas escolares no contexto belga. Os resultados encontrados por Range, Yonke e Young (2011) e Young et al. (2019) entre estudantes estadunidenses em cursos de formação de professores permitiram constatar que estes tinham crenças positivas sobre a reprovação, considerando o procedimento uma forma de prevenir e remediar as dificuldades de aprendizagem presentes e futuras, sendo também da opinião de que esse é o procedimento mais indicado para crianças imaturas.

Em Portugal, a formação inicial dos professores do $1^{\circ}$ ciclo do ensino básico está dividida em dois ciclos de ensino superior - licenciatura e mestrado —, sendo exigida a qualificação de mestrado para lecionar. A formação é concretizada por instituições politécnicas e universitárias, e um modelo sequencial é utilizado, no qual os estudantes realizam a componente educativa prática, isto é, o estágio profissional, apenas na parte final da formação (mestrado) (Almeida e Lopo, 2015). Não parece haver nenhuma investigação realizada em Portugal sobre as crenças relacionadas à reprovação dos estudantes em cursos de formação de professores. Além disso, nenhuma das investigações mencionadas anteriormente estudou as semelhanças ou diferenças entre as crenças dos futuros professores e as dos professores em serviço, de modo que pudesse oferecer alguma informação sobre como evoluem as crenças dos professores desde a sua formação até a sua integração na escola. No entanto, Marcoux, Boraita e Crahay (2016), em sua revisão dos estudos do programa de 
investigação liderado por Crahay, mencionam o estudo de Hausoul (2005), que acompanhou 19 estudantes dois anos após a sua entrada em serviço como professores, observando o efeito da integração nas crenças dos professores iniciantes. As crenças negativas iniciais relacionadas à reprovação não resistiram às pressões sociais do ambiente em que os jovens foram inseridos, que apresentava crenças mais positivas em relação à reprovação. Os professores iniciantes adaptaram as suas crenças àquelas dominantes, alguns mantendo as suas convicções pessoais enquanto adotavam as práticas esperadas pela instituição, isto é, reprovando os alunos, mesmo sem acreditar nos benefícios da reprovação (Marcoux, Boraita e Crahay, 2016).

\section{RELAÇÃO ENTRE AS CRENÇAS E AS PRÁTICAS DE REPROVAÇÃO}

A existência de culturas pedagógicas que promovem a construção e manutenção de crenças favoráveis à efetividade da reprovação é preocupante, pois diversos autores consideram que as crenças são os melhores indicadores das decisões individuais tomadas pelos professores na sua prática escolar (Borko, Roberts e Shavelson, 2008; Buehl e Beck, 2015). As suas crenças influenciam as suas percepções e juízos, afetando as práticas implementadas em sala de aula com o objetivo de ajudar o aluno a ultrapassar as suas dificuldades, bem como a decisão de reprovação ou transição no fim do ano escolar (Buehl e Beck, 2015; Barrett-Tatum, Ashworth e Scales, 2019). Embora os estudos que avaliem tanto as crenças dos professores como as suas práticas de reprovação sejam escassos, os poucos que existem indicam que as crenças positivas estão associadas a um maior uso da prática de reprovação. Bonvin (2003), por exemplo, identificou as crenças positivas dos professores sobre a reprovação como um dos principais preditores da prática de reprovação de alunos no $2^{\circ}$ ano de escolaridade. Da mesma forma, Range et al. (2012) referem que os professores e diretores de escola que já vivenciaram a reprovação se mostraram favoráveis à prática.

\section{COMPREENDER AS CRENÇAS SOBRE A REPROVAÇÃO}

A persistência das crenças positivas em relação à efetividade da reprovação, apesar dos resultados da investigação, intriga muitos teóricos e investigadores. De forma geral, a maioria das investigações associa a persistência dessas crenças à falta de conhecimento dos professores sobre a reprovação, adquirido por meio de formação ou de documentos formais de origem científica. O desconhecimento das investigações na área está associado a uma maior adesão do professor à reprovação, tanto em professores como em estudantes de cursos de formação (Witmer, Hoffman e Nottis, 2004; Crahay, Marbaise e Issaieva, 2013; Boraita, 2015; Ribeiro et al., 2018; Barrett-Tatum, Ashworth e Scales, 2019).

Apesar desses resultados, ainda se sabe pouco sobre como as crenças se desenvolvem e são mantidas no sistema de crenças dos professores, ou como se relacionam a variáveis socioprofissionais e à experiência do professor. Essa lacuna na literatura deve-se, em parte, ao fato de os instrumentos utilizados em muitos estudos serem compostos por itens de natureza diversa, cuja estrutura inter-relacional é desconhecida.Por exemplo, o Teachers' Perceptions about Retention Survey (TPRS), 
de Tomchin e Impara (1992), um dos questionários mais utilizados nas investigações (e.g., Bonvin, 2003; Witmer, Hoffman e Nottis, 2004; Range, Yonke e Young, 2011; Range et al., 2012; Barrett-Tatum, Ashworth e Scales, 2019; Santana, 2019; Young et al.,2019), inclui itens relacionados às razões para reter um aluno, razões para não reter um aluno, e questões sobre a efetividade da reprovação. O questionário não tem sido alvo de análises fatoriais, de modo que a sua estrutura inter-relacional é desconhecida, não sendo possível criar escalas-somadas que representem os múltiplos aspectos avaliados em uma única medida. Em consequência, esse tipo de instrumento é analisado item-a-item, aumentando o erro de medida, fazendo a estimação de modelos multivariados mais difícil e mascarando possíveis relações nos coeficientes correlacionais e nas comparações entre grupos (Hair et al., 2014). Além disso, o número elevado de indicadores eleva a complexidade dos modelos e dificulta a interpretação dos resultados, devido à redundância dos itens associados ao mesmo conceito (Hair et al., 2014). Consequentemente, as análises descritivas e majoritariamente bivariadas realizadas com esse tipo de questionário, apesar de úteis para descrever as crenças dos profissionais, limitam o estudo da relação entre as crenças sobre a reprovação e outras variáveis relevantes.

Pelo contrário, os estudos realizados pela equipe de Desenvolvimento e Intervenção em Situação Escolar (Développement Apprentissage et Intervention en Situation Scolaire - DAISS), da Universidade de Genebra, liderada por Crahay, Boraita e Marcoux (Crahay, Marbaise e Issaieva, 2013; Boraita, 2015; Boraita e Marcoux, 2016; Marcoux, Boraita e Crahay, 2016; Ribeiro et al., 2018), utilizam instrumentos com estruturas fatoriais estudadas e validadas por meio de técnicas psicométricas. As suas investigações revelaram a presença consistente de três componentes no sistema de crenças dos professores sobre a efetividade de reprovação: crenças da reprovação como regulador acadêmico, crenças sobre as suas consequências socioafetivas e crenças sobre os seus efeitos quando realizada precocemente. Essas crenças, apesar de correlacionadas, apresentam alguma independência entre si, sendo observados participantes que consideram a reprovação benéfica para a aprendizagem, mesmo temendo as suas consequências socioafetivas e vice-versa (Marcoux, Boraita e Crahay, 2016). A estrutura observada parece ser bastante semelhante em várias culturas ocidentais, tendo sido notada na Bélgica, na França e na Suíça (Boraita e Marcoux, 2016), assim como no Brasil (Ribeiro et al., 2018).

Os estudos realizados com instrumentos validados permitiram identificar que, além do conhecimento científico sobre a reprovação, a experiência na profissão docente e a experiência de reprovação do próprio professor também podem influenciar as suas crenças. Ribeiro et al. (2018) e Walton (2018) observaram que os professores com mais experiência têm crenças menos positivas sobre a reprovação, $o$ mesmo sucedendo com os professores que, ao longo da sua escolaridade, passaram por situações de reprovação (Ribeiro et al.,2018). A formação acadêmica parece ser outro fator determinante nas crenças dos professores (Ribeiro et al., 2018) e futuros professores em formação (Marcoux, Boraita e Crahay, 2016) sobre a reprovação escolar. Assim, os professores com mais formação (mestrado e doutorado) e os estudantes em cursos de formação mais avançados apresentaram crenças menos positivas em relação à reprovação escolar do que os seus colegas com menos formação. 


\section{CONTEXTO DO ESTUDO}

Este estudo teve como objetivo caracterizar e compreender as crenças de professores em serviço e futuros professores do $1^{\circ}$ ciclo do ensino básico português sobre reprovação no $2^{\circ}$ ano de escolaridade. $\mathrm{O} 1^{\circ}$ ciclo do ensino básico em Portugal dura 4 anos, sendo a idade esperada de frequência dos 6 aos 10 anos. Limitou-se este estudo apenas ao $2^{\circ}$ ano de escolaridade, por várias razões. Primeiro, os estudos indicam que as crenças e as práticas de reprovação podem variar em função do ano de escolaridade lecionado (e.g., Tomchin e Impara, 1992; Ribeiro et al., 2018; Santana, 2019). A segunda razão reside na elevada taxa de reprovação em Portugal nesse ano de escolaridade. Finalmente, escolhemos o $2^{\circ}$ ano por ser o primeiro ano escolar em que, por lei, a reprovação pode ser utilizada nas escolas portuguesas (Portugal, 2018).

Pretendeu-se responder às seguintes questões de investigação:

- Quais as crenças dos professores e dos futuros professores (estudantes em cursos de formação de professores) em relação à reprovação no $2^{\circ}$ ano de escolaridade, e como essas crenças estão estruturadas? Quais as semelhanças e diferenças entre essas crenças?

- Qual a percepção que os professores e futuros professores têm da efetividade e dificuldade de implementação da reprovação em comparação a outras medidas de intervenção para promover o sucesso escolar?

- Existe uma relação entre as crenças dos professores sobre a reprovação e as suas práticas de reprovação no $2^{\circ}$ ano de escolaridade?

- Que características socioprofissionais (idade, experiência e formação acadêmica) e experiências de reprovação dos participantes estão associadas às suas crenças sobre a reprovação no $2^{\circ}$ ano de escolaridade?

\section{MÉTODO}

\section{PARTICIPANTES}

Participaram deste estudo 137 professores de $1^{\circ}$ ciclo (58,1\% da amostra) e 99 estudantes de cursos de licenciatura ou mestrado do ensino de $1^{\circ}$ ciclo do ensino básico (41,9\% da amostra), cuja distribuição em função do sexo, habilitações e ano de formação está descrita no Tabela 1. Em ambos os grupos, a maioria dos participantes são do sexo feminino e apresentam habilitações ao nível da licenciatura. A maioria dos futuros professores está cursando o primeiro ou segundo ano do mestrado. Os professores apresentavam entre 25 e 65 anos (média $(M)=46,57$, desvio padrão (DP) $=8,59$ ), e de 1 a 42 anos de experiência profissional ( $M=22,00$, $\mathrm{DP}=10,18)$. Os estudantes tinham entre 19 e 49 anos $(\mathrm{M}=25,17, \mathrm{DP}=6,01)$.

\section{INSTRUMENTOS}

Para avaliar as crenças face à reprovação, foi utilizada uma versão revista da escala de Ribeiro et al. (2018), originalmente desenvolvida pela equipe de Crahay, Boraita e Marcoux (Marcoux, Boraita e Crahay, 2016). A escala está composta por 
Tabela 1 - Descrição da amostra.

\begin{tabular}{l|c|c|c|c|c|c|c}
\hline \multirow{2}{*}{ Variável } & \multirow{2}{*}{ Resposta } & \multicolumn{2}{|c|}{ Estudantes } & \multicolumn{2}{c|}{ Professores } & \multicolumn{2}{c}{ Total } \\
\cline { 2 - 8 } & & $\mathrm{f}$ & $\%$ & $\mathrm{f}$ & $\%$ & $\mathrm{f}$ & $\%$ \\
\hline \multirow{3}{*}{ Sexo } & Feminino & 98 & 99,0 & 129 & 94,2 & 227 & 96,2 \\
\hline & Masculino & 1 & 1,0 & 8 & 5,8 & 9 & 3,8 \\
\hline \multirow{3}{*}{ Habilitações } & Secundário & 30 & 30,3 & 0 & 0,0 & 30 & 12,7 \\
\cline { 2 - 9 } & Licenciatura & 68 & 68,7 & 88 & 64,2 & 156 & 66,1 \\
\cline { 2 - 9 } & Pós-graduação & 0 & 0,0 & 25 & 18,2 & 25 & 10,6 \\
\cline { 2 - 8 } & Mestrado & 1 & 1,0 & 24 & 17,5 & 25 & 10,6 \\
\hline \multirow{3}{*}{ Ano de formação } & Licenciatura, 20 ano & 19 & 19,2 & - & - & - & - \\
\cline { 2 - 8 } & Licenciatura, 30 ano & 11 & 11,1 & - & - & - & - \\
\cline { 2 - 8 } & Mestrado, $1^{\circ}$ ano & 33 & 33,3 & - & - & - & - \\
\cline { 2 - 8 } & Mestrado, $2^{\circ}$ ano & 35 & 35,4 & - & - & - & - \\
\cline { 2 - 8 } & Não indicado & 1 & 1,0 & - & - & - & - \\
\hline
\end{tabular}

f: frequência.

Fonte: Banco de dados da pesquisa.

15 afirmações relativas à efetividade da reprovação, respondidas por meio de uma escala de tipo Likert de cinco pontos (1=Discordo totalmente a $5=$ Concordo totalmente). Os itens apresentam uma estrutura inter-relacional que avalia três dimensões. $\mathrm{Na}$ dimensão acadêmica, são avaliadas as crenças sobre os efeitos acadêmicos gerais da reprovação no $2^{\circ}$ ano de escolaridade, isto é, os itens permitem avaliar a concordância de professores e futuros professores sobre a eficácia da reprovação na promoção do conhecimento e no envolvimento do aluno nas aprendizagens ( 9 itens, por exemplo, "A reprovação escolar é um meio eficaz de ajudar o aluno imaturo a alcançar os outros"). Na dimensão socioafetiva, os itens avaliam o impacto da reprovação na percepção de competência e na autoestima dos alunos (3 itens, por exemplo, "A reprovação escolar influencia negativamente a confiança que o aluno deveria ter em suas capacidades"). Finalmente, na dimensão reprovação precoce, são avaliadas as crenças sobre a efetividade da reprovação precoce, isto é, se a prática é mais efetiva quando realizada nos primeiros anos de escolaridade (3 itens, por exemplo, "Se o aluno precisa repetir o ano, é preferível que isso ocorra nos anos iniciais do ensino básico").Valores mais elevados indicam uma percepção positiva sobre a reprovação.

Foi também utilizado um segundo instrumento para avaliar a percepção que os professores tinham sobre a efetividade e dificuldade na implementação das medidas de intervenção para promoção do sucesso educativo. Essa escala foi construída com base nos estudos de Rodrigues et al. (2017), de Range et al. (2012), e nas medidas universais e seletivas descritas no decreto-lei n. 54 (Portugal, 2018). Ficou, assim, constituída por 12 itens: redução do número de alunos por turma; diferenciação pedagógica; acomodações curriculares (por exemplo: adaptações ao nível da organização da sala de aula, da apresentação de conteúdos...); promoção 
de competências sociais e emocionais; acompanhamento familiar e valorização da escola; intervenção em pequenos grupos; apoio individualizado; coadjuvação em sala de aula; reprovação; continuidade pedagógica (reprovação com acompanhamento do grupo); apoio psicopedagógico e/ou intervenção de outros técnicos e apoio tutorial. Solicitou-se aos professores que classificassem, em uma escala Likert, a efetividade ( $1=$ Nada efetivo a $5=$ Muito efetivo) e a dificuldade (1=Fácil de implementar a 5=Difícil de implementar) na concretização das 12 intervenções definidas para recuperar alunos com insucesso escolar.

Essas escalas foram antecedidas de uma nota introdutória, na qual foram referidos os objetivos da investigação, o caráter anônimo e confidencial das informações, o pedido de colaboração voluntário e uma declaração de consentimento informado. A última seção do questionário compreendia um conjunto de itens de resposta múltipla ou aberta, de forma a recolher informação relativa a dados biográficos (sexo e idade), habilitações acadêmicas e situação profissional (anos de serviço para os professores e anos de formação para os estudantes) dos participantes. Os participantes foram ainda questionados sobre a sua experiência com a reprovação, nomeadamente a sua opinião sobre as crenças dos colegas sobre a reprovação; experiências próprias de reprovação no seu percurso escolar; participação em formações ou leitura de literatura científica sobre reprovação; e as práticas de reprovação no último ano em que o professor foi titular do $2^{\circ}$ ano de escolaridade. Ainda foi questionado aos professores se estes se sentiam pressionados a promover os alunos.

\section{PROCEDIMENTOS}

Após aprovação da Comissão de Ética do Instituto Universitário (ISPA) (D/020/11/2019), o questionário eletrônico foi partilhado por meio de grupos de professores do $1^{\circ}$ ciclo de ensino básico nas redes sociais, e também com quatro centros de ensino universitário cuja oferta formativa incluía o ensino em educação básica.

Uma vez recolhidos os dados, a estrutura fatorial com três dimensões observada nos estudos de Ribeiro et al. (2018) foi avaliada na amostra do presente estudo, com recurso a uma análise fatorial confirmatória (AFC). Foi utilizado o estimador weighted least squares mean and variance adjusted (WLSMV), mais adequado para itens ordinais (Hair et al.,2014), sendo utilizado o software MPLUS para a análise. Uma vez que se desconhece a estrutura fatorial do segundo instrumento, esta foi avaliada por meio de uma análise fatorial exploratória (AFE). Foram observados os seguintes índices de ajustamento: a estatística de qui-quadrado $\left(\chi^{2}\right)$, o Comparative Fit Index (CFI), o Tucker Lewis Index (TLI) e o Root Mean Square Error of Approximation (RMSEA). Considerou-se que a estrutura fatorial dos itens era adequada à presente amostra se eram observados valores superiores a 0,95 no CFI e TLI, e valores iguais ou inferiores a 0,08 no RMSEA (Hair et al., 2014). A consistência interna foi avaliada através do composite reliability (CR), sendo considerados adequados valores superiores a 0,70 (Hair et al., 2014).

Uma vez confirmada a validade estrutural do instrumento, recorreu-se ao software SPSS (versão 26) para responder às questões de investigação. Realizou-se uma análise descritiva dos dados recolhidos, e foram calculados coeficientes de 
correlação de Pearson (para as variáveis intervalares), de Spearman (para variáveis ordinais) e de ponto bisserial (para as variáveis qualitativas dicotômicas). Uma vez que as dimensões do questionário de crenças sobre reprovação estão correlacionadas, foi utilizada uma análise de variância multivariada (MANOVA, F) para identificar as diferenças entre as crenças dos professores e as dos estudantes, bem como para comparar as percepções dos professores de acordo com a frequência de alunos do $2^{\circ}$ ano de escolaridade reprovados no último ano em que lecionaram esse ano de escolaridade. As comparações sobre a efetividade e dificuldade de implementação das diferentes intervenções foi realizada por meio de uma análise de variância para medidas repetidas (ANOVA, F), tendo sido realizados testes de contraste simples, com correção Bonferroni, com a reprovação como grupo de comparação. Nos testes multivariados, foi utilizado o traço de Pillai (V), uma vez que esse indicador é mais robusto à violação de pressupostos de normalidade e homogeneidade das variâncias (Hair et al.,2014). O tamanho do efeito foi avaliado através do eta parcial ao quadrado $\left(\eta_{\mathrm{p}}{ }^{2}\right)$, sendo utilizada a interpretação proposta por Cohen: $\eta_{\mathrm{p}}{ }^{2} \geq 0,01$ magnitude pequena, $\eta_{\mathrm{p}}{ }^{2} \geq 0,06$ média ou moderada, e $\eta_{\mathrm{p}}{ }^{2} \geq 0,14$ grande (Espírito-Santo e Daniel, 2018).

\section{RESULTADOS}

Para se poder dar resposta às questões de investigação colocadas, foram estudadas as propriedades psicométricas do instrumento de recolhimento de informação. Os resultados da AFC indicaram que a estrutura tridimensional da escala de crenças de Ribeiro et al. (2018) mostrou-se adequada para a amostra em estudo - $\chi^{2}(82)=214,91 ; \mathrm{CFI}=0,98 ; \mathrm{TLI}=0,97 ; \mathrm{RMSEA}=0,08$. As três dimensões também apresentaram níveis adequados de fiabilidade $-\mathrm{CR}>0,85$. $\mathrm{O}$ segundo instrumento apresentou uma estrutura fatorial que confirma a existência de duas dimensões: uma que avalia a percepção dos participantes sobre a efetividade das intervenções e outra sobre a dificuldades de implementação das intervenções. Os índices de ajustamento indicam que essa estrutura é adequada para a amostra em estudo $\left(\chi^{2}(229)=263,91 ; \mathrm{CFI}=0,97 ; \mathrm{TLI}=0,97 ; \mathrm{RMSEA}=0,06\right)$. Nesse instrumento também foram observados níveis adequados de fiabilidade $-\mathrm{CR}>0,80$.

\section{CRENÇAS DE PROFESSORES E ESTUDANTES}

\section{SOBRE A REPROVAÇÃO NO $2 .{ }^{\circ}$ ANO DE ESCOLARIDADE}

Para responder à primeira questão de investigação, foi realizada uma análise descritiva das três dimensões avaliadas (Tabela 2). As respostas dos participantes estão distribuídas ao longo de todo o intervalo da escala (1 a 5), indicando uma grande variabilidade nas crenças dos respondentes. Constata-se que, para o conjunto dos inquiridos, as crenças sobre a reprovação são mais positivas na dimensão reprovação precoce do que nas dimensões efeitos acadêmicos e afetivos. Esses participantes consideram, desse modo, que a reprovação é mais benéfica quando ocorre no início da escolaridade.

Para compreender melhor esses resultados, foi contabilizada, por um lado, a quantidade de participantes que apresentaram um grau elevado de concordância 
Tabela 2 - Estatísticas descritivas das crenças relacionadas à reprovação e testes de diferenças entre professores e estudantes.

\begin{tabular}{|c|c|c|c|c|c|c|c|c|c|}
\hline \multirow{2}{*}{$\begin{array}{l}\text { Dimensões } \\
\text { (teste de } \\
\text { diferenças) }\end{array}$} & \multirow[t]{2}{*}{ Participante } & \multirow[t]{2}{*}{$\mathrm{M}$} & \multirow[t]{2}{*}{ DP } & \multicolumn{2}{|c|}{$\begin{array}{c}\text { Crenças } \\
\text { negativas }\end{array}$} & \multicolumn{2}{|c|}{$\begin{array}{c}\text { Crenças } \\
\text { neutras }\end{array}$} & \multicolumn{2}{|c|}{$\begin{array}{l}\text { Crenças } \\
\text { positivas }\end{array}$} \\
\hline & & & & $\mathrm{f}$ & $\%$ & $\mathrm{f}$ & $\%$ & $f$ & $\%$ \\
\hline \multirow{3}{*}{$\begin{array}{l}\text { Efeitos } \\
\text { acadêmicos } \\
\left(\mathrm{F}(1 ; 226)=66,60^{* * *} ;\right. \\
\left.\eta_{\mathrm{p}}{ }^{2}=0,22\right)\end{array}$} & Estudantes & 2,79 & 0,81 & 23 & 23,2 & 62 & 62,6 & 14 & 14,1 \\
\hline & Professores & 3,63 & 0,81 & 7 & 5,1 & 57 & 41,6 & 73 & 53,3 \\
\hline & Total & 3,28 & 0,88 & 30 & 12,7 & 119 & 50,4 & 87 & 36,9 \\
\hline \multirow{3}{*}{$\begin{array}{l}\text { Efeitos } \\
\text { socioafetivos } \\
(\mathrm{F}(1 ; 226)= \\
\left.148.92^{* *} ; \eta_{\mathrm{p}}{ }^{2}=0,39\right)\end{array}$} & Estudantes & 2,24 & 0,83 & 66 & 66,7 & 25 & 25,3 & 8 & 8,1 \\
\hline & Professores & 3,69 & 0,94 & 15 & 10,9 & 32 & 23,4 & 90 & 65,7 \\
\hline & Total & 3,08 & 1,15 & 81 & 34,3 & 57 & 24,2 & 98 & 41,5 \\
\hline \multirow{3}{*}{$\begin{array}{l}\text { Reprovação } \\
\text { precoce } \\
\left(\mathrm{F}(1 ; 226)=56,19^{* *} ;\right. \\
\left.\eta_{\mathrm{p}}{ }^{2}=0,19\right)\end{array}$} & Estudantes & 3,43 & 0,96 & 18 & 18,2 & 32 & 32,3 & 49 & 49,5 \\
\hline & Professores & 4,34 & 0,89 & 8 & 5,8 & 11 & 8,0 & 118 & 86,1 \\
\hline & Total & 3,96 & 1,02 & 26 & 11,0 & 43 & 18,2 & 167 & 70,8 \\
\hline
\end{tabular}

M: média; DP: desvio padrão; F: ANOVA; $\eta_{\mathrm{p}}^{2:}$ eta parcial ao quadrado; $f$ frequência; ${ }^{*} \mathrm{p}<0,050 ;{ }^{* *} \mathrm{p}<0,001$.

Fonte: Banco de dados da pesquisa.

com a reprovação em cada uma das dimensões (valores superiores a 3,5) e que indicaram crenças positivas sobre a reprovação, e, por outro lado, os participantes que apresentaram um grau elevado de discordância (inferiores a 2,5), indicando crenças negativas sobre a reprovação. Considerou-se que os participantes com valores intermediários (entre 2,5 e 3,5) apresentavam crenças neutras ou pouco definidas, não tendo uma opinião formada sobre o assunto. Os resultados, que figuram na Tabela 2, indicam que, nas dimensões efeitos socioafetivos e reprovação precoce, existem mais participantes com crenças positivas que com crenças negativas em relação à reprovação. Na dimensão efeitos acadêmicos, cerca de 50\% dos respondentes têm crenças neutras.

A MANOVA revelou diferenças significativas entre as crenças dos estudantes e as dos professores - $F(3 ; 232)=50,61 ; V=0,40 ; p<0,001 ; \eta_{p}{ }^{2}=0,40$. Essas diferenças são observadas em todas as dimensões, como indicam os resultados das ANOVAs (F) apresentados na Tabela 2. Em todas as dimensões, os estudantes apresentaram crenças mais negativas sobre a reprovação no $2^{\circ}$ ano de escolaridade. Observamos, também, que o efeito é maior na dimensão socioafetiva, que apresenta valores mais elevados de $\eta_{\mathrm{p}}^{2}$. É na dimensão socioafetiva que se observa um maior número de estudantes com crenças negativas $(66,7 \%)$ comparativamente ao grupo de professores (10,9\%). Na dimensão dos efeitos acadêmicos gerais, observou-se que a maioria dos estudantes apresenta crenças neutras, mas é importante assinalar que, na dimensão reprovação precoce, esses estudantes também apresentaram crenças positivas $(49,5 \%)$, mesmo que a proporção não seja tão elevada como nos professores $(86,1 \%)$ (Tabela 2). 


\section{EFETIVIDADE E DIFICULDADE DE IMPLEMENTAÇÃO}

\section{DAS INTERVENÇÕES PARA PROMOVER O SUCESSO}

A MANOVA indica que existem diferenças significativas entre as opiniões dos professores e as dos alunos em relação à efetividade das diversas intervenções $\mathrm{F}(11 ; 148)=6,36 ; \mathrm{V}=0,32 ; \mathrm{p}<0,001 ; \eta_{\mathrm{p}}^{2}=0,32-$, motivo pelo qual foram realizadas análises independentes para cada grupo de participantes.

Nos alunos, as ANOVAs para medidas repetidas indicam que há diferenças no grau de efetividade indicado pelos professores para cada uma das intervenções apresentadas $-F(11 ; 46)=24,31 ; V=0,85 ; p<0,001 ; \eta_{p}{ }^{2}=0,85$. Os testes de contraste são apresentados na Tabela 3 , sendo considerados significativos os valores de $\mathrm{p}<.004$ (correção Bonferroni). Os resultados indicam que os estudantes consideram que qualquer uma das intervenções indicadas, com exceção da continuidade pedagógica, apresenta um nível de efetividade mais elevado que a reprovação. $\mathrm{O}$ acompanhamento à família, a intervenção em pequenos grupos, a promoção de competências sociais e emocionais, a redução do número de alunos por turma e o apoio individualizado são intervenções vistas como consideravelmente mais eficazes do que a reprovação $\left(\eta_{\mathrm{p}}^{2}>0,60\right)$.

Tabela 3 - Estatísticas descritivas da opinião dos participantes em relação à efetividade das intervenções para promover o sucesso escolar e testes de contrastes.

\begin{tabular}{|c|c|c|c|c|c|c|c|c|}
\hline \multirow[t]{2}{*}{ Intervenção } & \multicolumn{4}{|c|}{$\begin{array}{l}\text { Estudantes } \\
\qquad(n=57)\end{array}$} & \multicolumn{4}{|c|}{$\begin{array}{l}\text { Professores } \\
\qquad(n=103)\end{array}$} \\
\hline & $\mathrm{M}$ & $\mathrm{DP}$ & $F(1 ; 56)^{a}$ & $\eta_{p}^{2 a}$ & $\mathrm{M}$ & $\mathrm{DP}$ & $\mathrm{F}(1 ; 102)^{\mathrm{a}}$ & $\eta_{p}^{2 a}$ \\
\hline $\begin{array}{l}\text { Redução do número de } \\
\text { alunos }\end{array}$ & 4,51 & 0,78 & $121,86^{*}$ & 0,68 & 4,58 & 0,92 & $31,26^{*}$ & 0,23 \\
\hline Diferenciação pedagógica & 4,05 & 1,25 & $66,42^{*}$ & 0,54 & 4,50 & 0,77 & $27,25^{\prime \prime}$ & 0,21 \\
\hline Acomodações curriculares & 4,30 & 0,80 & $77,34^{*}$ & 0,58 & 4,20 & 0,92 & 8,01 & 0,07 \\
\hline $\begin{array}{l}\text { Promoção de competências } \\
\text { sociais e emocionais }\end{array}$ & 4,47 & 0,66 & $127,95^{*}$ & 0,70 & 4,25 & 0,83 & $12,40^{*}$ & 0,11 \\
\hline $\begin{array}{l}\text { Acompanhamento familiar } \\
\text { e valorização da escola }\end{array}$ & 4,65 & 0,58 & $138,64^{*}$ & 0,71 & 4,47 & 0,80 & $27,31^{*}$ & 0,21 \\
\hline Intervenção em grupo & 4,49 & 0,60 & $137,35^{*}$ & 0,71 & 4,54 & 0,71 & $36,24^{*}$ & 0,26 \\
\hline Apoio individualizado & 4,51 & 0,76 & $115,20^{*}$ & 0,67 & 4,58 & 0,73 & $41,39^{*}$ & 0,29 \\
\hline Coadjuvação em sala de aula & 3,97 & 0,96 & $44,84^{*}$ & 0,44 & 4,21 & 1,18 & 7,61 & 0,07 \\
\hline Continuidade pedagógica & 2,88 & 1,15 & 5,95 & 0,10 & 2,93 & 1,52 & $25,48^{*}$ & 0,20 \\
\hline Apoio psicopedagógico & 4,11 & 0,82 & $68,84^{*}$ & 0,55 & 4,41 & 0,89 & $23,98^{*}$ & 0,19 \\
\hline Apoio tutorial & 4,09 & 0,91 & $55,33^{*}$ & 0,50 & 3,89 & 1,10 & 0,87 & 0,01 \\
\hline Reprovação & 2,52 & 1,15 & $-^{\mathrm{b}}$ & $-^{\mathrm{b}}$ & 3,76 & 1,29 & $-^{\mathrm{b}}$ & $-^{\mathrm{b}}$ \\
\hline
\end{tabular}

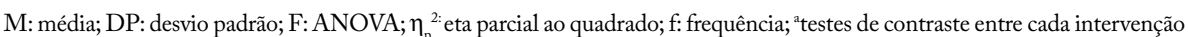
e a reprovação; 'brupo de referência; ${ }^{\mathrm{p}} \mathrm{p}<0,004$ (correção Bonferroni).

Fonte: Banco de dados da pesquisa. 
Nos professores também foram observadas diferenças significativas nos níveis de efetividade indicados para as diferentes intervenções - $\mathrm{F}(11 ; 92)=14,13 ; \mathrm{V}=0,62$; $\mathrm{p}<0,001 ; \eta_{\mathrm{p}}{ }^{2}=0,63$. Existem diferenças significativas entre a eficácia indicada para a reprovação e a eficácia indicada para as outras intervenções, mas essas diferenças são menores que as observadas nos estudantes $\left(\eta_{\mathrm{p}}{ }^{2}<0,30\right)$. Isso deve-se ao fato dos professores terem atribuído à reprovação um score médio mais elevado $(3,76)$ do que os estudantes $(2,52)$ (Tabela 3$)$. Os professores apresentaram crenças bastante positivas (valores médios iguais ou acima de 4,41 , sendo que o valor máximo era 5 , e o tamanho de efeito elevado $\left.\eta_{\mathrm{p}}^{2}>0,14\right)$ relativamente ao apoio individualizado, à intervenção em pequenos grupos, à redução do número de alunos por turma, à diferenciação pedagógica, ao acompanhamento familiar e ao apoio psicopedagógico, que são consideradas intervenções mais efetivas que a reprovação. Com valores ligeiramente inferiores (entre 3,76 e 4,21), os professores ainda indicam níveis semelhantes de efetividade para as acomodações curriculares, a coadjuvação em sala de aula, o apoio tutorial e a reprovação. A única intervenção que apresentou um score abaixo do ponto médio é a continuidade pedagógica $(2,93)$. Desse modo, esse grupo de professores considera que as crianças, quando são reprovadas, não devem acompanhar o seu grupo turma, devendo juntar-se ao novo grupo de alunos do $2^{\circ}$ ano de escolaridade (Tabela 3).

Relativamente à dificuldade de implementação das medidas de intervenção, observaram-se também diferenças entre as opiniões de professores e estudantes $F(11 ; 146)=2,63 ; V=0,16 ; p=0,004 ; \eta_{p}{ }^{2}=0,16$. Para os estudantes, foram observadas diferenças significativas no grau de dificuldade indicado para cada medida de intervenção $-F(11 ; 46)=4,21 ; V=0,50 ; p<0,001 ; \eta_{p}{ }^{2}=0,50$. Os testes de contraste, apresentados na Tabela 4 , indicaram que os estudantes consideram que a redução do número de alunos, a diferenciação pedagógica, o apoio psicopedagógico, o apoio individualizado, a coadjuvação em sala de aula e o acompanhamento familiar são mais dificeis de implementar que a reprovação $\left(\eta_{\mathrm{p}}^{2}>0,14\right)$. Consideram ainda os estudantes que a aplicação da reprovação apresenta o mesmo grau de dificuldade que as seguintes intervenções para promover o sucesso: acomodações curriculares, promoção de competências sociais e emocionais, intervenção em pequenos grupos, continuidade pedagógica e apoio tutorial (Tabela 4).

No caso dos professores, também se observaram diferenças significativas no grau de dificuldade indicado para cada uma das intervenções $-\mathrm{F}(11 ; 90)=5,58 ; \mathrm{V}=0,41$; $\mathrm{p}<0,001 ; \eta_{\mathrm{p}}{ }^{2}=0,41$. Os testes de contraste indicaram que apenas a redução do número de alunos por turma é considerada mais difícil de aplicar que a reprovação (Tabela 4). Todas as outras intervenções são consideradas pelos professores como apresentando aproximadamente o mesmo grau de dificuldade de implementação que a reprovação.

\section{RELAÇÃO ENTRE AS CRENÇAS DOS}

\section{PROFESSORES E AS SUAS PRÁTICAS DE REPROVAÇÃO}

Constatou-se que a taxa de reprovação era bastante alta entre os professores que já foram titulares do $2^{\circ}$ ano no passado $(n=127)$ : no último ano em que lecionaram esse ano escolar, $33,9 \%$ dos professores reteve um aluno e $26 \%$ reteve dois ou 
Tabela 4-Estatísticas descritivas da opinião dos participantes sobre a dificuldade de implementar as intervenções para promover o sucesso escolar e testes de contrastes.

\begin{tabular}{l|c|c|c|c|c|c|c|c}
\hline \multirow{2}{*}{\begin{tabular}{l} 
Intervenção \\
\cline { 2 - 10 }
\end{tabular}} & \multicolumn{4}{|c|}{$\begin{array}{c}\text { Estudantes } \\
(\mathrm{n}=57)\end{array}$} & \multicolumn{5}{c}{$\begin{array}{c}\text { Professores } \\
(\mathrm{n}=101)\end{array}$} \\
\cline { 2 - 10 } $\begin{array}{l}\text { Redução do número de } \\
\text { alunos }\end{array}$ & 3,81 & 1,06 & $39,00^{*}$ & 0,41 & 3,92 & 1,55 & $20,95^{*}$ & 0,17 \\
\hline Diferenciação pedagógica & 3,40 & 1,27 & $16,52^{*}$ & 0,23 & 2,95 & 1,32 & 1,04 & 0,01 \\
\hline Acomodações curriculares & 2,96 & 1,09 & 5,02 & 0,08 & 2,75 & 1,24 & 4,32 & 0,04 \\
\hline $\begin{array}{l}\text { Promoção de competências } \\
\text { sociais e emocionais }\end{array}$ & 2,81 & 1,14 & 3,47 & 0,06 & 2,92 & 1,21 & 1,48 & 0,01 \\
\hline $\begin{array}{l}\text { Acompanhamento familiar e } \\
\text { valorização da escola }\end{array}$ & 3,18 & 1,12 & $9,90^{*}$ & 0,15 & 3,51 & 1,22 & 6,71 & 0,06 \\
\hline Intervenção em grupo & 2,68 & 1,27 & 1,21 & 0,02 & 2,99 & 1,33 & 0,68 & 0,01 \\
\hline Apoio individualizado & 3,37 & 1,20 & $13,31^{*}$ & 0,19 & 3,06 & 1,38 & 0,16 & 0,00 \\
\hline Coadjuvação em sala de aula & 3,20 & 1,02 & $11,79^{*}$ & 0,17 & 3,14 & 1,39 & 0,02 & 0,00 \\
\hline Continuidade pedagógica & 2,93 & 1,19 & 6,20 & 0,10 & 3,23 & 1,42 & 0,75 & 0,01 \\
\hline Apoio psicopedagógico & 3,19 & 0,90 & $13,71^{*}$ & 0,20 & 3,19 & 1,40 & 0,19 & 0,00 \\
\hline Apoio tutorial & 3,04 & 1,07 & 7,90 & 0,12 & 3,26 & 1,35 & 0,71 & 0,01 \\
\hline Reprovação & 2,44 & 1,28 & $-{ }^{\mathrm{b}}$ & $-^{\mathrm{b}}$ & 3,12 & 1,42 & $-{ }^{\mathrm{b}}$ & $-^{\mathrm{b}}$ \\
\hline
\end{tabular}

M: média; DP: desvio padrão; F: ANOVA; $\eta_{\mathrm{p}}{ }^{2:}$ eta parcial ao quadrado; ${ }^{a}$ testes de contraste entre cada intervenção e a reprovação; ${ }^{b}$ grupo de referência; ${ }^{*} \mathrm{p}<0,004$ (correção Bonferroni).

Fonte: Banco de dados da pesquisa.

mais alunos. Apenas 40,1\% dos professores não retiveram qualquer aluno. Quando se compararam as crenças dos professores que tinham e os que não tinham reprovado alunos, os resultados da MANOVA indicaram que existiam diferenças nas suas crenças sobre a reprovação $\left(F(6 ; 246)=2,35 ; \mathrm{V}=0,11 ; \mathrm{p}=0,031, \eta_{\mathrm{p}}{ }^{2}=0,05\right)$. Os resultados das análises univariadas, apresentadas na Tabela 5 , indicam que as diferenças são apenas significativas nas dimensões relativas aos efeitos socioafetivos (um efeito médio), e à reprovação precoce (um efeito pequeno). Quando comparados com os professores que não reprovaram alunos, os professores que reprovaram dois ou mais alunos apresentaram crenças significativamente mais positivas em relação aos efeitos da reprovação no $2^{\circ}$ ano no desenvolvimento socioafetivo $(\mathrm{p}=0,007)$ - e nos efeitos da reprovação precoce $(p=0,027)$. Os professores que reprovaram um aluno apresentaram crenças mais positivas apenas na dimensão reprovação precoce $(\mathrm{p}=0,029)$.

\section{RELAÇÃO ENTRE AS CRENÇAS E AS CARACTERÍSTICAS DOS PARTICIPANTES}

$\mathrm{Na}$ Tabela 6, pode ser observada a distribuição das respostas dos professores e estudantes às questões sobre as suas experiências com a reprovação. Constatou-se uma elevada taxa de participantes com experiências de reprovação, com taxas similares às identificadas nos estudos do Programme for International Students Assessment 
Tabela 5 - Estatísticas descritivas das crenças relacionadas à reprovação e testes de diferenças em função das práticas de reprovação dos professores.

\begin{tabular}{l|c|c|c|c|c}
\hline \multirow{2}{*}{ Dimensões } & $\begin{array}{c}\text { Número de alunos } \\
\text { reprovados }\end{array}$ & $\mathrm{M}$ & $\mathrm{DP}$ & $\mathrm{F}(2,123)$ & $\eta_{\mathrm{p}}{ }^{2}$ \\
\hline \multirow{3}{*}{ Efeitos acadêmicos } & Nenhum & 3,62 & 0,91 & 0,65 & 0,01 \\
\cline { 2 - 6 } & Um aluno & 3,63 & 0,72 & & \\
\cline { 2 - 6 } & Dois alunos ou mais & 3,81 & 0,71 & & \\
\hline \multirow{3}{*}{ Efeitos socioafetivos } & Nenhum & 3,45 & 1,05 & $4,17^{*}$ & 0,06 \\
\cline { 2 - 6 } & Um aluno & 3,81 & 0,81 & & \\
\cline { 2 - 6 } & Dois alunos ou mais & 4,00 & 0,69 & & \\
\hline \multirow{3}{*}{ Reprovação precoce } & Nenhum & 4,19 & 1,08 & $3,47^{*}$ & 0,05 \\
\cline { 2 - 6 } & Um aluno & 4,55 & 0,51 & & \\
\cline { 2 - 6 } & Dois alunos ou mais & 4,59 & 0,52 & & \\
\hline
\end{tabular}

Nenhum: $n=51$; Um aluno: $n=43$; Dois alunos ou mais: $n=33$; M: média; DP: desvio padrão; $F$ : ANOVA; $\eta_{\mathrm{p}}^{2:}$ eta parcial ao quadrado; $" \mathrm{p}<0,050$.

Fonte: Banco de dados da pesquisa.

Tabela 6 - Estatísticas descritivas das experiências de reprovação dos participantes.

\begin{tabular}{l|c|c|c|c|c}
\hline \multirow{2}{*}{ Variáveis } & \multirow{2}{*}{ Respostas } & \multicolumn{2}{|c|}{ Estudantes } & \multicolumn{2}{c}{ Professores } \\
\cline { 3 - 6 } & & $\mathrm{f}$ & $\%$ & $\mathrm{f}$ & $\%$ \\
\hline $\begin{array}{l}\text { Participantes com experiência própria de } \\
\text { reprovação ao longo da sua trajetória escolar }\end{array}$ & & 36 & 39,6 & 44 & 32,4 \\
\hline $\begin{array}{l}\text { Participantes com formação ou leitura de } \\
\text { literatura científica sobre reprovação }\end{array}$ & & 30 & 34,1 & 115 & 84,6 \\
\hline \multirow{4}{*}{$\begin{array}{l}\text { Os meus colegas têm uma opinião } \\
\text { favorável sobre a reprovação }\end{array}$} & $\begin{array}{c}\text { Discordo } \\
\text { totalmente }\end{array}$ & 6 & 6,7 & 3 & 2,2 \\
\cline { 2 - 6 } & Discordo & 15 & 16,7 & 13 & 9,6 \\
\cline { 2 - 6 } & Neutro & 59 & 65,6 & 26 & 19,1 \\
\cline { 2 - 6 } & Concordo & 8 & 8,9 & 56 & 41,2 \\
\cline { 2 - 6 } & $\begin{array}{c}\text { Concordo } \\
\text { totalmente }\end{array}$ & 2 & 2,2 & 38 & 27,9 \\
\hline \multirow{3}{*}{$\begin{array}{c}\text { Sinto-me pressionado a promover alunos } \\
\text { que ainda não estão preparados para o ano } \\
\text { de escolaridade seguinte }\end{array}$} & $\begin{array}{c}\text { Discordo } \\
\text { totalmente }\end{array}$ & - & - & 12 & 8,8 \\
\cline { 2 - 6 } & Discordo & - & - & 10 & 7,4 \\
\cline { 2 - 6 } & Neutro & - & - & 12 & 8,8 \\
\cline { 2 - 6 } & Concordo & - & - & 49 & 36,0 \\
\hline & $\begin{array}{c}\text { Concordo } \\
\text { totalmente }\end{array}$ & - & - & 53 & 39,0 \\
\hline
\end{tabular}

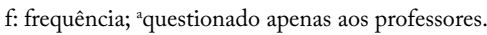

Fonte: Banco de dados da pesquisa. 
(PISA) (OECD, 2016). Também verificamos que a maioria dos professores concorda que os seus colegas têm uma opinião favorável sobre a reprovação e que se sentem pressionados a promover alunos que consideram que deveriam ser reprovados.

Os coeficientes de correlação entre as crenças relacionadas à reprovação, as variáveis socioprofissionais e as experiências de reprovação estão apresentados na Tabela 7. Destaca-se que, no grupo dos futuros professores, quanto maior era a sua idade, as suas habilitações acadêmicas e o número de anos no curso, mais negativas eram as suas crenças sobre a reprovação no $2^{\circ}$ ano de escolaridade, especialmente no que se refere aos seus efeitos acadêmicos gerais e à reprovação precoce. Além disso, quanto mais os estudantes consideravam que os seus colegas apresentavam uma opinião favorável sobre a reprovação, mais positivas também eram as suas crenças sobre os efeitos acadêmicos gerais e socioafetivos da reprovação.

Tabela 7 - Correlação entre as crenças sobre a reprovação e as variáveis socioprofissionais.

\begin{tabular}{|c|c|c|c|c|c|c|}
\hline \multirow[b]{2}{*}{ Variáveis } & \multicolumn{3}{|c|}{ Estudantes } & \multicolumn{3}{|c|}{ Professores } \\
\hline & $\begin{array}{l}\text { Efeitos } \\
\text { gerais }\end{array}$ & $\begin{array}{l}\text { Efeitos } \\
\text { socio- } \\
\text { afetivos }\end{array}$ & $\begin{array}{c}\text { Reprovação } \\
\text { precoce }\end{array}$ & $\begin{array}{l}\text { Efeitos } \\
\text { gerais }\end{array}$ & $\begin{array}{l}\text { Efeitos } \\
\text { socio- } \\
\text { afetivos }\end{array}$ & $\begin{array}{c}\text { Reprovação } \\
\text { precoce }\end{array}$ \\
\hline Idade $^{\mathrm{a}}$ & $-0,36^{* *}$ & $-0,25^{*}$ & $-0,28^{* *}$ & $-0,08$ & $-0,03$ & $-0,09$ \\
\hline Habilitações $^{b}$ & $-0,36^{* *}$ & 0,05 & $-0,25^{*}$ & $-0,03$ & $-0,14$ & $-0,14$ \\
\hline $\begin{array}{l}\text { Anos de } \\
\text { formação }^{\mathrm{b}}\end{array}$ & $-0,32^{* *}$ & $-0,11$ & $-0,25^{*}$ & - & - & - \\
\hline $\begin{array}{l}\text { Anos de } \\
\text { serviço }^{\text {a }}\end{array}$ & - & - & - & $-0,02$ & 0,01 & $-0,05$ \\
\hline $\begin{array}{l}\text { Experiência } \\
\text { própria de } \\
\text { reprovação }{ }^{c}\end{array}$ & 0,09 & 0,10 & 0,14 & 0,02 & 0,05 & 0,05 \\
\hline $\begin{array}{l}\text { Conhecimento } \\
\text { da literatura } \\
\text { científica sobre } \\
\text { reprovação }{ }^{c}\end{array}$ & $-0,02$ & 0,02 & $-0,08$ & $-0,03$ & $-0,10$ & $-0,10$ \\
\hline $\begin{array}{l}\text { Opinião } \\
\text { favorável dos } \\
\text { colegas sobre a } \\
\text { reprovação }\end{array}$ & $0,36^{* * *}$ & $0,24^{*}$ & 0,13 & $0,40^{* *}$ & $0,22^{* *}$ & $0,35^{* *}$ \\
\hline $\begin{array}{l}\text { Pressão na } \\
\text { promoção de } \\
\text { alunos }\end{array}$ & - & - & - & $0,28^{* *}$ & 0,13 & $0,31^{* *}$ \\
\hline
\end{tabular}

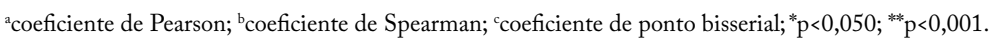

Fonte: Banco de dados da pesquisa.

Já no que se refere ao grupo dos professores, não se observaram correlações significativas entre as suas crenças sobre reprovação e as suas características socioprofissionais (idade, habilitações acadêmicas ou anos de serviço). Contudo, constatou-se que, quanto mais os professores pensavam que os colegas tinham uma opinião positiva sobre a reprovação, mais positivas eram também as suas crenças, sendo o efeito maior do que nos estudantes e para todas as dimensões avaliadas. 
Também, quanto mais positivas as suas crenças sobre a efetividade acadêmica e sobre a reprovação precoce, maior a pressão sentida para promover alunos que não consideram preparados para o ano de escolaridade seguinte. A leitura de literatura científica sobre reprovação não esteve associada às crenças nem dos professores nem dos estudantes.

\section{DISCUSSÃO}

Esse estudo teve como objetivo caracterizar e compreender as crenças de professores e estudantes do curso de formação do $1^{\circ}$ ciclo do ensino básico português em relação à reprovação no $2^{\circ}$ ano de escolaridade. Respondendo a nossa primeira questão de investigação, os resultados indicaram que as crenças dos professores podem se estruturar nas três dimensões observadas nos estudos de Boraita e Marcoux (2016) e de Ribeiro et al. (2018), nomeadamente crenças sobre a efetividade da reprovação como regulador acadêmico, sobre as suas consequências socioemocionais e sobre os seus efeitos nos primeiros anos de escolaridade. Os resultados também apontaram para crenças positivas sobre a reprovação por parte dos inquiridos, especialmente no que se refere à dimensão reprovação precoce, o que é coerente com os resultados encontrados em outros países (Bonvin, 2003; Boraita e Marcoux, 2016; Ribeiro et al., 2018) e em Portugal (Rodrigues et al., 2017; Santana, 2019). Tomchin e Impara (1992) sugerem que os professores acreditam que os alunos precisam de uma base sólida nas habilidades fundamentais, considerando aceitável a reprovação dos alunos que não conseguem dominar essas habilidades básicas nos primeiros anos de escolaridade. Para os participantes na presente pesquisa, se a reprovação é necessária, esta deve ocorrer no $1^{\circ}$ ciclo, de preferência no $1^{\circ}$ ano, pois entendem ser um meio eficaz para evitar fracassos nos níveis de ensino mais elevados. Respondendo ainda à primeira questão de investigação, o presente estudo encontrou claras diferenças entre os professores e os estudantes no que se refere aos benefícios da reprovação. Os professores apresentaram, em média, crenças mais positivas do que os estudantes, sendo esses resultados semelhantes aos de outros países com elevadas taxas de reprovação, como Suíça (Bonvin, 2003), Bélgica (Crahay, Marbaise e Issaieva, 2013), Estados Unidos (Range et al., 2012) e Brasil (Ribeiro et al., 2018). Pelo contrário, os estudantes apresentaram uma visão mais neutra em relação aos efeitos acadêmicos gerais, consideraram que a reprovação tem efeitos negativos no desenvolvimento socioafetivo dos alunos, mas ainda apresentam uma visão favorável da reprovação precoce. Esses resultados são semelhantes aos observados por Boraita e Marcoux (2016) na Suíça, cujos professores apresentaram crenças mais neutras do que positivas. A presença de crenças mais neutras e negativas nos estudantes pode ser um indicador dos efeitos da formação e da transmissão do conhecimento dos efeitos negativos da reprovação, associadas às políticas nacionais de redução das taxas de reprovação (CNE, 2015). Essa hipótese é reforçada pela presença de correlações negativas entre os anos de formação e as crenças positivas da reprovação.

Um dos contributos do presente estudo é o fato de se ter comparado a opinião dos professores e futuros professores relativamente à eficácia e à dificuldade de implementação de diversas intervenções promotoras do sucesso escolar com as 
suas crenças sobre implementação da reprovação, uma área na qual existem ainda poucos estudos (Range et al., 2012). Os dados confirmam os resultados da nossa primeira questão de investigação, isto é, que os professores consideram a reprovação mais efetiva do que os futuros professores. Respondendo especificamente à nossa segunda questão de investigação, e relativamente à eficácia das intervenções, os professores e os futuros professores consideram que existem outras intervenções mais eficazes que a reprovação, por exemplo, a diferenciação pedagógica, a intervenção em pequeno grupo e o envolvimento parental. Essas são consideradas pelos estudos científicos mais eficazes e com menores consequências negativas para os alunos do que a reprovação (Hattie, 2009). Se, a esse fato, juntarmos as considerações de Buehl e Beck (2015) e Pajares (1992), que ponderam a existência de uma associação entre as crenças e as práticas pedagógicas dos professores, podemos esperar que esses professores implementem as intervenções por eles consideradas mais eficazes e que são consonantes com a literatura (Hattie, 2009). Isso seria positivo, porque indicaria que os professores implementam intervenções eficazes para a diminuição das dificuldades dos alunos. Os resultados também demonstraram que a prática considerada menos eficaz pelos professores era a continuidade pedagógica, não concordando que crianças reprovadas acompanhem o seu grupo turma. E possível que os professores acreditem que a eficácia pedagógica poderia ser aumentada se os professores se deparassem com classes mais homogêneas, como sugere Crahay (2007), apesar de não existirem evidências científicas que corroborem essa crença (Crahay, 2007). Pelo contrário, os estudos indicam que a heterogeneidade dos grupos poderá favorecer o desenvolvimento cognitivo do aluno e o clima de aprendizagem na sala de aula (Decristan et al., 2017).

No que se refere ao grau de dificuldade da intervenção, os estudantes consideraram a reprovação mais fácil de implementar que outras intervenções. Anteriormente, Range et al. (2012) e Young et al. (2019) tinham sugerido que a reprovação poderia ser considerada mais fácil de implementar por se tratar de um processo meramente administrativo, no qual os alunos reprovados simplesmente repetem os mesmos conteúdos no ano letivo seguinte. No entanto, quando comparados com os futuros professores, os professores acreditam que implementar a reprovação é mais difícil. Essas diferenças podem ser explicadas pelas vivências distintas dos professores, que, tal como referem no nosso questionário, se sentem pressionados a promover os alunos. Essa pressão poderá estar relacionada às políticas educativas que procuram reduzir as taxas de reprovação observadas nos estudos internacionais do PISA (CNE, 2015).

No que se refere à relação entre as crenças de reprovação dos professores e as suas práticas, a nossa terceira questão de investigação, o presente estudo confirmou a existência de uma associação significativa. Os professores que reprovaram um ou mais alunos no $2^{\circ}$ ano de escolaridade apresentaram crenças mais positivas em relação aos seus efeitos socioafetivos e à sua efetividade quando realizada precocemente do que os professores que não reprovaram alunos. Esses resultados são coerentes com a teoria da tomada de decisão (Borko, Roberts e Shavelson, 2008) e com os resultados obtidos por Bonvin (2003). Conjugando esses dados com a análise descritiva das crenças dos professores sobre as intervenções para recuperar alunos com insucesso acadêmico, os resultados parecem sugerir que os professores tenderão 
a utilizar a prática da reprovação com maior frequência porque acreditam que esta é tão fácil de implementar quanto outras intervenções, que é eficaz (especialmente quando realizada nos primeiros anos), e que não tem muitas consequências negativas.

Face aos resultados obtidos, particularmente ao nível dos professores, considera-se necessário sensibilizar os professores em relação às consequências negativas associadas à reprovação, especialmente em longo prazo, uma vez que os estudos indicam que alunos reprovados têm maior probabilidade de ser reprovados novamente no seu percurso escolar e de abandonar a escola precocemente (Hughes et al., 2017; Hughes et al., 2018). Essa prática deixa uma marca profunda nos alunos, minando o seu desempenho e bem-estar emocional e diminuindo o seu autoconceito (Ferrão, 2015; Peixoto et al., 2016).

Os resultados relativos à quarta questão de investigação também permitiram identificar algumas características socioprofissionais que estão associadas às crenças dos professores e estudantes. No caso dos professores, as crenças sobre reprovação não parecem estar relacionadas aos seus anos de serviço, contrariamente ao observado em outras investigações (Ribeiro et al.,2018; Walton, 2018). Uma vez que as crenças só mudam como resultado do envolvimento em práticas sociais relevantes (Kagan, 1992; Skott, 2015), esses resultados podem ser indicadores de que os professores das escolas portuguesas continuam a promover a reprovação como uma prática eficaz, independentemente dos anos que têm de ensino. Da mesma forma, apesar de uma porcentagem importante dos inquiridos afirmar ter lido artigos científicos sobre os efeitos de reprovação, não encontramos evidência de que esse conhecimento da leitura científica esteja associado a crenças mais negativas sobre a implementação dessa medida. Isso é coerente com estudos anteriores, nos quais a maioria dos professores demonstrou não ter conhecimento dos resultados das investigações sobre reprovação, e, quando esse conhecimento existia, confiavam mais no seu conhecimento prático (as suas experiências e as experiências dos seus colegas) do que nos resultados da investigação (Witmer, Hoffman e Nottis, 2004; Crahay, Marbaise e Issaieva, 2013; Barrett-Tatum, Ashworth e Scales, 2019). Como Kagan (1992, p. 76) indica, algumas crenças são bastante "persistentes" mesmo com a apresentação de evidências contraditórias, e esse parece ser o caso das crenças sobre a reprovação. Para utilizar a terminologia construtivista de Skott (2015), a acomodação do conhecimento científico nas crenças dos professores parece não ser facilmente realizada.

No caso dos estudantes, observou-se que tanto a idade quanto as habilitações e os anos de formação estão relacionados negativamente às crenças de reprovação. Esses resultados parecem sugerir que a formação dos professores poderá diminuir as crenças positivas sobre a efetividade da prática da reprovação. O estudo de Boraita (2013) já tinha destacado que as crenças iniciais sobre a reprovação de um grupo de estudantes (neutras) se alteravam pela participação em um módulo de formação teórica com estágio prático na intervenção com alunos com dificuldades escolares. Após o estágio prático, os estudantes tinham passado a acreditar menos nas vantagens da reprovação. Todavia, os escassos estudos longitudinais realizados até agora parecem sugerir que essas crenças negativas não se mantêm após a sua entrada no mercado de trabalho (Marcoux, Boraita e Crahay, 2016), em um contexto escolar no qual muitos dos profissionais apresentam crenças positivas sobre a reprovação, 
adaptando suas crenças àquelas que são dominantes ao seu redor. As crenças dos professores sobre o que os colegas pensam acerca da reprovação parecem ser mais relevantes na formação das suas crenças do que, por exemplo, a formação e a leitura de resultados da investigação científica, pois as crenças tendem a refletir a interpretação da comunidade (Skott, 2015). É possível que, como sugerido pelo CNE (2015), exista uma cultura de reprovação em Portugal, e que as crenças e os estereótipos passem de geração em geração porque os professores mais novos acreditam que os professores com mais experiência são modelos que deverão seguir no que se refere à forma de atuar dentro da escola, na sala de aula e ainda no que se refere às políticas educativas (Caria, 2007).

Esta investigação apresenta, contudo, um conjunto de limitações que deverão ser consideradas na interpretação dos resultados e no delineamento de futuros estudos. A amostra é pequena e desconhece-se o contexto em que os professores desenvolveram as suas crenças e práticas, o que impossibilita a generalização dos resultados. Além disso, as informações sobre as práticas de reprovação não foram delimitadas no tempo, nem foi controlado o contexto socioeconômico em que ocorreram. Essa informação é relevante, pois as crenças dos professores em relação à reprovação e a sua relação com as práticas não podem ser entendidas fora do contexto no qual elas se desenvolvem (Buehl e Beck, 2015; Walton, 2018). Assim, futuros estudos deverão contextualizar as crenças e práticas, considerando os fatores externos (o contexto da sala de aula, da escola, fatores regionais e nacionais) que podem funcionar como facilitadores ou como obstáculos da expressão das crenças dos professores nas suas práticas, tal como sugere Buehl e Beck (2015). Adicionalmente, o caráter correlacional e o delineamento transversal do estudo não permitem determinar relações causa-efeito, nem compreender se realmente a formação acadêmica ou a experiência profissional tem um efeito significativo nas crenças e práticas dos professores. Serão necessários estudos longitudinais que analisem as alterações das crenças dos professores ao longo do seu percurso formativo e profissional.

\section{CONSIDERAÇÕES FINAIS}

A problemática da reprovação no atual sistema educativo português tem-se revelado controversa relativamente aos benefícios que essa prática pedagógica pode trazer em termos de aprendizagem. No entanto, são-lhe reconhecidas várias desvantagens que levam a considerar que a reprovação não é muito eficaz. Tendo isso em consideração, bem como os resultados obtidos neste estudo, e ainda as altas taxas de reprovação observadas neste ano escolar, considera-se necessário um trabalho formativo com os professores em serviço, que promova a reflexão crítica sobre as crenças e práticas de reprovação, de forma a desenvolver práticas de promoção de sucesso escolar alternativas. Acreditamos que um trabalho contínuo com os professores na implementação de medidas formativas de combate ao insucesso escolar (por exemplo, diferenciação pedagógica, acomodações curriculares e intervenção em pequeno grupo) permitirão reduzir a reprovação, melhorar as aprendizagens dos alunos e diversificar as estratégias de ensino dos professores. 


\section{AGRADECIMENTOS}

Agradecemos a colaboração da equipe de Crahay, na Universidade de Genebra, e ao Centro de Estudos e Pesquisas em Educação, Cultura e Ação Comunitária, pela partilha do questionário de crenças relacionadas à reprovação.

\section{REFERÊNCIAS}

ALLEN, C. S.; CHEN, Q.; WILLSON, V. L.; HUGHES, J. N. Quality of research design moderates effects of grade retention on achievement: a meta-analytic, multilevel analysis. Educational Evaluation and Policy Analysis, Washington, DC, v. 31, n. 4, p. 480-499, 2009. Disponível em: https://doi.org/10.3102/0162373709352239. Acesso em: 5 fev. 2018.

ALMEIDA, S.; LOPO, T. T. Parte II: Tendências de organização curricular da formação inicial de professores do $1^{\circ} \mathrm{e}$ do $2^{\circ}$ ciclos do ensino básico. In: CONSELHO NACIONAL DE EDUCAÇÃO. Formação inicial de professores. Lisboa: Faro: CNE; Universidade do Algarve, 2015. p. 85-139. (Coleção Seminários e Colóquios). Disponível em: https://www.cnedu.pt/content/edicoes/seminarios_e_coloquios/ LivroCNE_FormacaoInicialProfessores_10dezembro2015.pdf. Acesso em: 1 fev. 2021. BARRETT-TATUM, J.; ASHWORTH, K.; SCALES, D. Gateway literacy retention policies: perspectives and implications from the field. International Journal of Education Policy and Leadership, Fairfax, v. 15, n. 10, 2019. Disponível em: https:// doi.org/10.22230/ijepl.2019v15n10a845. Acesso em: 2 abr. 2020.

BONVIN, P. The role of teacher attitudes and judgement in decision-making: the case of grade retention. European Educational Research Journal, Washington, DC, v. 2, n. 2, p. 277-94, 2003. Disponível em: https://journals.sagepub.com/doi/pdf/10.2304/ eerj.2003.2.2.6. Acesso em: 20 fev. 2018.

BORAITA, F. Effet d'un module de formation sur les croyances de futurs enseignants eu égard au redoublement: étude qualitative à l'Université de Genève. Revue Suisse des Sciences de l'Éducation, Fribourg, v. 35, n. 2, p. 347-69,2013. Disponível em: https:// doi.org/10.24452/sjer.35.2.4915. Acesso em: 24 mar. 2020.

BORAITA, F. Les croyances de futurs enseignants sur le redoublement au regard de leurs connaissances sur ses effets et de leurs conceptions psychopédagogiques. Revue des Sciences de l'Éducation, Montreal, v. 41, n. 3, p. 483-508, 2015. Disponível em: https://doi.org/10.7202/1035314ar. Acesso em: 28 abr. 2019.

BORAITA, F.; MARCOUX, G. Croyances à propos du redoublement de futurs enseignants entrant en formation dans différents contextes éducatifs. Éducation Comparée, Sèvres, v. 16, p. 91-115, 2016. Disponível em: https://doi. org/10.7202\%2F1024465ar. Acesso em: 4 abr. 2019.

BORKO, H.; ROBERTS, S.; SHAVELSON, R. Teachers' decision making: from Alan J. Bishop to today. In: CLARKSON, P.; PRESMEG, N. Critical issues in Mathematics Education. Boston: Springer, 2008. p. 37-67. Disponível em: https:// doi.org/10.1007/978-0-387-09673-5. Acesso em: 22 mar. 2019. 
BUEHL, M.; BECK,J.The relationship between teachers'beliefs and teachers' practices. In: FIVES, H.; GILL, M. G. (eds.). International handbook of research on teachers' beliefs. Nova York: Routledge, 2015. p. 66-84.

CARIA,T.H. A cultura profissional do professor de ensino básico em Portugal: uma linha de investigação em desenvolvimento. Sísifo-Revista de Ciências da Educação, Lisboa, v. 3,p. 125-138, 2007. Disponível em: http://sisifo.ie.ulisboa.pt/index.php/sisifo/article/viewFile/ 68/92. Acesso em: 15 abr. 2020.

CNE - CONSELHO NACIONAL DE EDUCAÇÃO. Relatório técnico: retenção nos ensino básico e secundário. Lisboa: Conselho Nacional de Educação, 2015. Disponível em: http://www.cnedu.pt/content/noticias/CNE/Relatorio_Tecnico_-_ Retencao.pdf. Acesso em: 22 mar. 2018.

CRAHAY, M. Qual pedagogia para os alunos em dificuldades escolar? Cadernos de Pesquisa, São Paulo, v. 37, n. 130, p. 181-208. 2007. Disponível em: https://doi. org/10.1590/S0100-15742007000100009. Acesso em: 22 mar. 2018.

CRAHAY, M.; MARBAISE, C.; ISSAIEVA, É. What is teachers'belief in the virtues of student retention founded on? Giornale Italiano Della Ricerca Educativa, Lecce, v. 6, n. 11, p. 75-94, 2013. Disponível em: https:/ojs.pensamultimedia.it/index.php/ sird/article/view/186/174. Acesso em: 23 mar. 2019.

DECRISTAN, J.; FAUTH, B.; KUNTER, M.; BÜTTNER, G.; KLIEME, E. The interplay between class heterogeneity and teaching quality in primary school. International Journal of Educational Research, Amsterdam, v. 86, p. 109-121, 2017. Disponível em: https://doi.org/10.1016/j.ijer.2017.09.004. Acesso em: 11 fev. 2021.

DGEEC - DIREÇÃO-GERAL DE ESTATÍSTICAS DA EDUCAÇÃO E CIÊNCIA. Taxa de retenção e desistência (\%), por sexo, nível de ensino, ciclo de estudos e ano de escolaridade - Continente, NUTS II, III e Conselhos - 2003/04 a 2017/18. [online]: Direção-Geral de Estatísticas da Educação e Ciência, 2019. Disponível em: https://www.dgeec.mec.pt/np4/96/\%7B\$clientServletPath\%7D/?ne wsId $=145 \&$ fileName=EE2019_TxTransicao_TxRetencao_PRT.XLSX. Acesso em: 13 nov. 2019.

ESPÍRITO-SANTO, H.; DANIEL, F. Calculating and reporting effect sizes on scientific papers (3): guide to report regression models and ANOVA effect sizes. Portuguese Journal of Behavioral and Social Research, Coimbra, v. 4, n. 1, p. 43-60, 2018. Disponível em: https://doi.org/10.31211/rpics.2018.4.1.72. Acesso em: 14 abr. 2020.

EURYDICE - EDUCATION,AUDIOVISUAL AND CULTURAL EXECUTIVE AGENCY. Grade retention during compulsory education in Europe: regulations and statistics. Brussels: Education, Audiovisual and Cultural Executive Agency, 2011. Disponível em: https:/op.europa.eu/en/publication-detail/-/publication/10f1486012a3-4f9e-b10a-32bee875420d. Acesso em: 22 fev. 2018.

FERRÃO, M. E. Tópicos sobre retenção escolar em Portugal através do PISA: qualidade e equidade. Education Policy Analysis Archives, Phoenix, v. 23, n. 114, 2015. Disponível em: https://doi.org/10.14507/epaa.v23.2091. Acesso em: 1 dez.2018. 
GOOS, M.; BELFI, B.; DE FRAINE, B.; VAN DAMME,J.; ONGHENA,P.; PETRY, K. Effectiveness of grade retention in primary and secondary education: a systematic review and meta-analysis. Pedagogische Studien, Enschede, v. 90, n. 5, p. 17-30, 2013a. Disponível em: https://doi.org/10.1016\%2Fj.edurev.2021.100401. Acesso em: 16 fev. 2018. GOOS, M.; SCHREIER, B. M.; KNIPPRATH, H. M.; DE FRAINE, B.; VAN DAMME, J.; TRAUTWEIN, U. How Can Cross-Country Differences in the Practice of Grade Retention Be Explained? A Closer Look at National Educational Policy Factors. Comparative Education Review, Amherst, v. 57, n. 1, p. 54-84, 2013 b. Disponível em: https://doi.org/10.1086/667655. Acesso em: 16 fev. 2018.

HAIR, J.; BLACK, W.; BABIN, B.; ANDERSON, R. Multivariate data analysis. Harlow: Pearson, 2014.

HATTIE, J. Visible learning: a synthesis of over 800 meta-analyses relating to achievement. London: Routledge, 2009.

HERMANS, R.; VAN BRAAK, J.; VAN KEER, H. Development of the beliefs about primary education scale: distinguishing a developmental and transmissive dimension. Teaching and Teacher Education, London, v. 24, n. 1, p. 127-139, 2008. Disponível em: https://doi.org/10.1016/j.tate.2006.11.007. Acesso em: 3 jun. 2019.

HUGHES, J.; CAO, Q.; WEST, S.; SMITH, P. A.; CERDA, C. Effect of retention in elementary grades on dropping out of school early. Journal of School Psychology, London, v. 65, p. 11-27, 2017. Disponível em: https://doi.org/10.1016/J. JSP.2017.06.003. Acesso em: 2 nov. 2018.

HUGHES, J.;WEST, S.; KIM, H.; BAUER, S. Effect of early grade retention on school completion: a prospective study. Journal of Educational Psychology, Washington, DC, v. 110, n. 7, p. 974-991, 2018. Disponível em: https://doi.org/10.1037/edu0000243. Acesso em: 2 nov. 2018.

KAGAN, D. M.Implications of research on teachers' belief. Educational psychologist, v.27,n.1, p.65-90,1992.Disponível em: https://doi.org/10.1207/s15326985ep2701_6. Acesso em: 3 mar. 2020.

MARCOUX, G.; BORAITA, F.; CRAHAY, M. À propos de la structuration de l'enracinem ent culturel et de la modifiabilité des croyances des enseignants sur le redoublement: synthèse d'un programme de recherche FNS. Schweizerische Zeitschrift Für Bildungswissenschaften, v. 38, n. 2, p. 367-384, 2016. Disponível em: https://doi. org/10.24452\%2Fsjer.38.2.4984. Acesso em: 3 mar. 2020.

NUNES, L. C.; REIS, A. B.; SEABRA, C. Is retention beneficial to low-achieving students? Evidence from Portugal. Applied Economics, Londres, v. 50, n. 40, p. 1-12, 2018. Disponível em: https://doi.org/10.1080/00036846.2018.1444261. Acesso em:22 mar.2018. OECD - ORGANISATION FOR ECONOMIC CO-OPERATION AND DEVELOPMENT. Low-performing students: why they fall behind and how to help them succeed. Paris: OECD Publishing, 2016. Disponível em: https://doi. org/10.1787/9789264250246-en. Acesso em: 22 fev. 2018.

PAJARES, F. Teachers' beliefs and educational research: Cleaning up a messy construct. Review of Educational Research, Washington, DC, v. 62, n. 3, p. 307-32, 1992. Disponível em: https://doi.org/10.3102/00346543062003307. Acesso em: 1 abril 2019. 
PEIXOTO, F.; MONTEIRO, V.; MATA, L.; SANCHES, C.; PIPA, J.; ALMEIDA, L. S. "To be or not to be retained... That's the question!" Retention, self-esteem, selfconcept, achievement goals, and grades. Frontiers in Psychology, Lausanne, v. 7, n. 1.550, 2016. Disponível em: https://doi.org/10.3389/fpsyg.2016.01550. Acesso em: 22 mar. 2018.

PORTUGAL. Despacho normativo n. 1-F, de 5 de abril de 2016. Regulamenta o regime de avaliação e certificação das aprendizagens desenvolvidas pelos alunos do ensino básico, bem como as medidas de promoção do sucesso educativo que podem ser adotadas no acompanhamento e desenvolvimento das aprendizagens. Diário da República, $2^{\mathrm{a}}$ série, n. 66, 5 abr. 2016. Disponível em: https://dre.pt/home/-/dre/74059570/details/maxim ized?serie=II\&dreId=74059567. Acesso em: 31 ago. 2021.

PORTUGAL. Despacho normativo n. 6, de 12 de abril de 2018. Estabelece os procedimentos da matrícula e respetiva renovação e as normas a observar na distribuição de crianças e alunos. Diário da República, 2a série, n. 72,12 abr. 2018. Disponível em: https://dre.pt/pesquisa/-/search/115093805/details/normal?1=1. Acesso em: 31 ago. 2021.

RANGE, B.; PIJANOWSKI, J.; HOLT, C.; YOUNG, S. The perceptions of primary grade teachers and elementary principals about the effectiveness of grade-level retention. Professional Educator, Auburn, v. 36, n. 1, p. 1-16, 2012. Disponível em: http://files. eric.ed.gov/fulltext/EJ989520.pdf. Acesso em: 17 fev. 2018.

RANGE, B.; YONKE, D. D.; YOUNG, S. Preservice teacher beliefs about retention: how do they know what they don't know? Journal of Research in Education, Washington, DC, v. 21, n. 2, p. 77-99, 2011. Disponível em: https://files.eric.ed.gov/ fulltext/EJ1098386.pdf. Acesso em: 16 fev. 2018.

RIBEIRO, V. M.; KASMIRSKI, P. R.; GUSMÃO, J. B.; BATISTA, A. A.; JANOMINI, M. A.; CRAHAY, M. Crenças de professores sobre reprovação escolar. Educação em Revista, Belo Horizonte, n. 34, e173086, 2018. Disponível em: https:// doi.org/10.1590/0102-4698173086. Acesso em: 25 mar. 2019.

RODRIGUES, M. L.; ALÇADA, I.; CALÇADA, T.; MATA, J. Apresentação de resultados do projeto Aprender a Ler e a Escrever em Portugal. Relatório de Progresso. Lisboa: Direção-Geral de Estatísticas em Educação e Ciência, 2017. Disponível em: http://www.epis.pt/upload/documents/592d4bcd461d4.pdf. Acesso em: 17 fev. 2018.

SANTANA, M. R. Práticas e representações acerca da retenção escolar. 2019. Tese (Doutorado em Ciências de Educação) - Universidade Nova de Lisboa, Lisboa, 2019. Disponível em: https://run.unl.pt/handle/10362/89715. Acesso em: 13 jan. 2020.

SKOTT, J. The promises, problems, and prospects of research on teachers' beliefs. In: FIVES, H.; GILL, M. G. (eds.). International Handbook of Research on Teachers' Beliefs. Nova York: Routledge, 2015. p. 13-30.

TOMCHIN, E.; IMPARA, J. Unraveling teachers' beliefs about grade retention. American Educational Research Journal, Washington, DC, v. 29, n. 1, p. 199-223, 1992. Disponível em: https://doi.org/10.3102/00028312029001199. Acesso em: 2 nov. 2018. 
WALTON, E. Teacher beliefs about grade repetition: an exploratory South African study. Citizenship Teaching \& Learning, United Kingdom, v. 13, n. 1, p. 45-60, 2018. Disponível em: https://doi.org/10.1386/ctl.13.1.45_1. Acesso em: 19 abr. 2019.

WITMER, S.; HOFFMAN, L.; NOTTIS, K. Elementary teachers' beliefs and knowledge about grade repetition: how do we know what they know? Education, Washington, DC, v. 125, n. 2, p. 173-94, 2004.

YOUNG, S.; TRUJILLO, N.P.; BRUCE, M.A.; POLLARD, T.; JONES, J.; RANGE, B. Preservice teachers' views about grade retention as an intervention for struggling students. Preventing School Failure: Alternative Education for Children and Youth, London, v. 63, n. 2, p. 113-120, 2019. Disponível em: https://doi.org/10.1080/10459 88X.2018.1523124. Acesso em: 3 mar. 2020.

\section{SOBRE AS AUTORAS}

Natalie Nóbrega Santos é doutoranda em Educação pelo ISPA Instituto Universitário, em associação com a Universidade Nova de Lisboa através das Faculdades de Ciências Sociais e Humanas (FCSH) e Faculdade de Ciências e Tecnologia (FCT), desenvolvendo as suas atividades de investigação no Centro de Investigação em Educação (CIE - ISPA).

E-mail: nsantos@ispa.pt

Vera Cristina Monteiro é doutora em Psicologia da Educação pela Faculdade de Ciências da Universidade de Lisboa. Docente no Instituto Universitário (ISPA) e membro do Centro de Investigação em Educação (CIE - ISPA).

E-mail: veram@ispa.pt

Conflitos de interesse: As autoras declaram que não possuem nenhum interesse comercial ou associativo que represente conflito de interesses em relação ao manuscrito.

Financiamento: Este estudo foi financiado pela Fundação da Ciência e da Tecnologia (FCT), SFRH/BD/139973/2018 e UIDP/04853/2020.

Contribuições dos autores: Santos, N. N.: Conceituação, Curadoria de Dados, Escrita

- Primeira Redação, Escrita Investigação, Metodologia, Recursos; Monteiro, V.: Revisão e Edição, Supervisão.

Recebido em 26 de agosto de 2020 Aprovado em 22 de fevereiro de 2021 